\title{
A PERSPECTIVA DA VIOLÊNCIA PSICOLÓGICA CONTRA A MULHER À LUZ DA OBRA "A MOÇA TECELÃ"1
}

Sylviane da Silva Sousa ${ }^{2}$

Centro Universitário Santo Agostinho-UNIFSA

\section{RESUMO}

O presente estudo aborda a violência psicológica contra a mulher tendo como plano de fundo a obra A moça tecelã, de Marina Colasanti, de forma a demonstrar suas perspectivas na sociedade, relacionando a forma de desenvolvimento da situação de violência vivenciada pela personagem na obra, com a vivenciada pela mulher contemporânea, tendo em vista que a ocorrência da violência psicológica se dar de maneira silenciosa e sutil, bem como as medidas a serem adotadas para que haja o seu combate de forma eficaz, e que muitas vezes ela acontece no âmbito familiar/conjugal. Faz-se importante e necessário debater sobre a temática afim de que a incidência desse tipo de violência ganhe maior notoriedade social, e que sua identificação seja imediata e coibida por meio de instrumentos jurídicos eficazes. Dentre os tipos de violência contra a mulher, a psicológica é uma das que encontra bastante discussão a cerca da sua ocorrência, vez que geralmente se dar por meio de comentários muitas vezes não vistos como maldosos ou com o objetivo de atingir negativamente a mulher, mas que acabam por interferir tanto na sua autoestima, como também na sua maneira de se portar diante de situações que podem lhe ser pejorativas de alguma maneira. As soluções encontradas para se evitar a construção dessa espécie de violência não se impõem tão eficazmente, uma vez que esta se encontra intimamente ligada a ideia do patriarcalismo, que por muito tempo perpetuou-se e continua instalada no meio social contemporâneo, mesmo com os avanços e conquistas das mulheres.

Palavras-Chave: Violência contra mulher. Violência psicológica. Patriarcalismo. A moça tecelã.

\section{INTRODUÇÃO}

O presente estudo aborda o conto de Marina Colasanti (2000) chamado "A moça Tecelã", que se trata inicialmente de uma obra literária com características de conto de fadas, porém no decorrer da narrativa percebe-se que se estabelece uma estrutura de dominação entre os sexos, relativamente aos personagens, e que tal estrutura consiste em um problema social atualmente.

A obra trás a debate assuntos relativamente à independência feminina frente à dominação masculina, cuja se manifesta por meio da violência psicológica. É relatado o dia a dia de uma moça capaz de criar e transformar tudo que almeja através de sua

\footnotetext{
${ }^{1}$ Trabalho apresentado no Congresso Brasileiro Ciência e Sociedade (CBCS 2019), promovido pelo Centro Universitário Santo Agostinho, de 03 a 05 de outubro de 2019, em Teresina-PI.

${ }^{2}$ Acadêmica do Curso de Bacharelado em Direito do Centro Universitário Santo Agostinho - UNIFSA. E- 


\section{CONGRESSO CIENCIAESOCIEDADE

máquina de tear mágica. Ela vivia sua vida de forma livre, independente, e poderia tecer tudo que imaginava para realizar seus desejos e suprir suas necessidades básicas.

O conto é repleto de metáforas e metalinguagens, já que o tear representa a vida da tecelã, a qual vive de forma intensa para realizar seus desejos a fim de proporcionar sua alegria, sendo um símbolo de altivez e independência de uma mulher que, a princípio, vivia sozinha, porém não necessitava de um companheiro para ser feliz ou sentir-se realizada.

É necessário observar a importância do estudo da violência psicológica relacionando a literatura com o aspecto jurídico aplicável à situação concreta, vez que os elementos literários ressaltam ainda mais os detalhes da realidade, dando-lhe um tratamento além do superficial, possibilitando uma compreensão essencial diferenciada da forma comum com que a violência é tratada na sociedade.

A literatura perfaz-se ímpar ao possibilitar contribuições inestimáveis ao instituto essencial à administração da justiça que terá suas normas aplicadas às situações concretas, evitando assim que o sistema jurídico se torne estagnado frente às sucessivas mudanças que ocorrem em meio às relações sociais.

O problema da pesquisa consiste na equiparação da violência sofrida pela personagem na obra, e pela mulher nos dias de hoje, bem como enfatizar as medidas necessárias para evitar sua ocorrência em âmbito familiar/conjugal, sob o ponto de vista da obra A moça tecelã, tendo em vista que sua incidência é silenciosa e sutil. $O$ estudo objetiva apontar as peculiaridades da violência psicológica, os aspectos do agressor e da vítima, através da revisão da literatura e da bibliografia em Direito Penal sobre sua incidência no âmbito social contemporâneo, comparativamente com a obra.

A relevância do estudo é a possibilidade de discussão que permite ampla percepção da temática, tendo em vista os pontos de amparo, quais sejam a literatura e o arcabouço normativo, permitindo o embasamento de estudos acadêmicos na área jurídica, abordando uma obra bastante atual, já que aborda a violência psicológica sob um aspecto incontroverso que exprime sutileza e crueldade concomitantemente. 


\section{CONGERSSOCIENCIAESOCIEDADE \\ Inovação, Diversidaade e Sustentahililitaile}

\section{METODOLOGIA}

O presente estudo foi desenvolvido por meio de uma pesquisa bibliográfica em Direito penal, especificamente sobre a violência psicológica, abordando de forma paralela os aspectos tratados na obra "A moça Tecelã".

O método de abordagem utilizado foi o indutivo, uma vez que parte de situações específicas para discussão no decorrer do estudo, ou seja, vai partir de uma situação particular para o geral.

\section{CONTEXTO HISTÓRICO DA VIOLÊNCIA CONTRA A MULHER}

Nas relações estabelecidas entre homem e mulher denotam-se, desde os primórdios, uma situação de controle e subordinação da figura feminina em face da figura masculina, uma das causas da violência contra a mulher, fato este que é histórico e pertencente à sociedade que adota parâmetros estabelecidos como uma ordem ideal para a constituição de uma família, de acordo com a realidade patriarcal.

Essa relação de poder estabelecida entre os gêneros pode desencadear a discriminação e opressão do considerado mais forte sobre o mais fraco, disseminando assim valores construídos de forma totalmente inversa e em desfavor das mulheres, disseminados tanto no meio social em que se inserem quanto no meio familiar.

Compreender a construção de papéis femininos e masculinos é imprescindível para analisar as relações de poder que se estabelecem entre eles. Nesse caso, as questões de gênero sustentam o desejo masculino de dominar e manter o controle da relação em face da mulher e da família. Assim, quando o homem sente-se destituído desse poder, passa a agir de forma violenta, pois sente a necessidade de dominar a qualquer custo, utilizando-se da força bruta como um instrumento dominador, para subjugar a parceira a cumprir seu "destino" de mulher, pré-estabelecido por valores patriarcais perpetuados na sociedade.

Essas formas de violências e discriminação são históricas, tornando-se naturais não só ao agressor como também para a vítima. São ataques diretos à integridade, 


\section{CONGEESSOC CIENCIAESOCIEDADE

desenvolvimento psíquico, saúde, liberdade e vida da mulher, que afetam não só

a sua estrutura física, mas principalmente psicológica. Nesta entoada, Saffioti (2001) explica a forma de como se dar o exercício da violência pelo homem que detém de um poder que lhe é inerente devido aos próprios valores disseminados pela cultura machista.

No exercício da função patriarcal, os homens detêm o poder de determinar a conduta das categorias sociais nomeadas, recebendo autorização ou, pelo menos, tolerância da sociedade para punir o que se lhes apresenta como desvio. Ainda que não haja nenhuma tentativa, por parte das vítimas potenciais, de trilhar caminhos diversos do prescrito pelas normas sociais, a execução do projeto de dominaçãoexploração da categoria social homens exige que sua capacidade de mando seja auxiliada pela violência. (SAFFIOTI, 2001, p. 115)

A violência conjugal durante muito tempo esteve incluída de forma natural na conduta da família considerada como moralmente correta. Primeiramente a mulher se submetia aos comandos do pai para depois se sujeitar aos do marido, e isso era um pensamento dominante, tanto que nenhuma norma ou lei existia para proibir a agressão sofrida por esta.

\section{A MOÇA TECELÃ: O CONTO SOBRE A VIOLÊNCIA PSICOLÓGICA}

A obra literária de Marina Colasanti (2000) embasa o presente estudo e conta a história de uma moça sonhadora que vive a tecer o seu mundo. Ao mesmo tempo em que a personagem é um símbolo de leveza, delicadeza e atenciosidade, de modo que representa originalmente a figura feminina, por outro lado ela se mostra independente, determinada e comprometida com cada detalhe de suas ações que aperfeiçoavam cada vez mais seus dias.

No conto, uma jovem tecelã vive sozinha em sua casa e em contato com a natureza. Tudo que deseja materializa-se. Enfatiza-se na obra que nada falta à moça, vez que seu tear lhe supria de tudo, com isso ela vive sempre tranquila. 


\section{cONWEESSOC CIENCIAESOCIEDADE

Nada Ihe faltava. Na hora da fome tecia um lindo peixe, com cuidado de escamas. E eis que o peixe estava na mesa, pronto para ser comido. Se sede vinha. Suave era a lã cor de leite que entremeava o tapete. E à noite, depois e lançar seu fio de escuridão, dormia tranquila. (COLASANTI, 2000 p. 10).

Porém, um dia ela sente-se sozinha e logo pensa que uma companhia iria the fazer bem, então tece para si um marido. Ansiosa, ela nem espera o dia seguinte e começa a tecer o físico do homem que não demora em se transformar no seu opressor. A própria descrição de como ela tece já evidencia a aparência de um homem dominador. De cima para baixo ela tece seu marido e põe em evidência a imposição do corpo do homem com uma nobreza indiscutível: "E aos poucos seu desejo foi aparecendo, chapéu emplumado, rosto barbado, corpo aprumado, sapato engraxado. Estava justamente acabando de entremear o último fio da ponta dos sapatos, quando bateram à porta." (COLASANTI, 2000, p. 12).

Bordieu explica que a dominação tem o dever de ficar evidenciada e ela se inscreve no corpo de forma que fique explícito o homem independente, livre de qualquer pressão externa.

Ser homem, no sentido de vir, implica um dever-ser, uma virtus, que se impõe sob a forma do "é evidente por si mesma", sem discussão. Semelhante à nobreza, a honra- que se inscreveu no corpo sob forma de um conjunto de disposições aparentemente naturais, muitas vezes visíveis na maneira peculiar de manter em pé, de aprumar o corpo, de erguer a cabeça, de uma atitude, uma postura, às quais corresponde de uma maneira de pensar e agir, um éthos, uma crença etc. - governa o homem de honra, independentemente de qualquer pressão externa. (BORDIEU, 2002, p. 31).

A partir do primeiro momento em que o homem aparece na história, ele já impõe sua atitude dominadora, visto que a moça nem precisa abrir a porta para ele entrar. Basta apenas ser materializado, nem mesmo a tempo de concluir seu feitio, e vai logo entrando na vida da personagem. "Nem precisou abrir. O moço meteu a mão na maçaneta, tirou o chapéu de pluma, e foi entrando na sua vida." (COLASANTI, 2000, p. 12). 
Em um relacionamento conjugal, o homem se impõe como superior, assumindo uma posição de poder no qual se instaura a violência simbólica. A ordem patriarcal da sociedade coloca a mulher em uma situação de submissão frente ao homem em vários aspectos, desde o âmbito familiar ao profissional.

O homem exige que a moça teça uma casa maior, e a moça, sem contestá-lo, obedece. "-Uma casa melhor é necessária - disse para a mulher. E parecia justo, agora que eram dois." (COLASANTI, 2000, p. 12). Vale salientar que, de todas as qualidades e características que ela poderia ter tecido no marido, a moça esquece-se de planejar o seu psicológico, a sua personalidade, tecendo apenas um homem como ele é em sua forma física.

Com o passar do tempo, o autoritarismo e ganância do homem aumentam: "Mas pronta a casa, já não lhe pareceu suficiente. - Para que ter casa se podemos ter palácio? - perguntou. Sem querer resposta, imediatamente ordenou que fosse de pedra com arremates de prata." (COLASANTI, 2000, p.12-13). Implementa-se nessa relação um tipo de violência silenciosa que ocorre de maneira sutil. Para Chauí essa tipologia é caracterizada como violência simbólica, como bem afirma:

A violência simbólica se institui por intermédio da adesão que o dominado não pode deixar de conceder ao dominante (e, portanto, à dominação) quando ele não dispõe, para pensá-la e para se pensar, ou melhor, para pensar sua relação com ele, mais que de instrumentos de conhecimento que ambos têm em comum e que, não sendo mais que a forma incorporada da relação de dominação, fazem esta relação ser vista como natural. (CHAUÍ, 1985, p. 47).

Chauí observa que a maneira do dominado de comportar-se, vendo a si próprio com o olhar opressor, e apenas aceitá-lo, facilita a dominação por seus opressores, visto que esta relação se torna natural. A peculiaridade da violência psicológica encontra-se na sua frequência, pois sua inserção na rotina se dar de maneira imperceptível, tendo em vista o grau de afinidade do agressor com a vítima, que geralmente são os companheiros. 


\title{
CONGEESSOC CIENCIAESOCIEDADE

A violência psicológica tem como enfoque destruir gradativamente a autoestima da vítima, subtraindo a sua capacidade de resistência, bem como sua identidade, fazendo com que haja uma progressão quanto aos estágios de violência sofrida por mulheres.

Conformada com a sua condição, ela continua a querer tecer. "Tecer era tudo o que fazia. Tecer era tudo o que queria fazer." (COLASANTI, 2000, p. 13). Por mais que ela se sinta mal em trabalhar sem descanso a serviço do seu marido, a moça não quer parar de tecer para ele, já que ela toma aquela atividade como uma obrigação para com o marido, a fim de buscar uma harmonia entre eles. A violência simbólica tem essa lógica: o dominado cumpre com "felicidade" tarefas subordinadas a ele. Para uma melhor compreensão, Chauí (1985) dispõe:

\begin{abstract}
A lógica, essencialmente social, do que chamamos de "vocação", tem por efeito produzir tais encontros harmoniosos entre as disposições e as posições, encontros que fazem com que as vítimas da dominação simbólica posam cumprir com felicidade (no duplo sentido do termo) as tarefas subordinadas ou subalternas que lhes são atribuídas por suas virtudes de submissão, de gentileza, de docilidade, de devotamento e de abnegação (CHAUÍ, 1985, p. 72-73).
\end{abstract}

Da mesma forma que no início da narrativa ela traz o tempo em que se sente sozinha e quer uma companhia a ponto de tecer um marido, chegando ao final da narrativa a moça também traz o tempo em que sua tristeza com a exploração de seu companheiro é maior que todas as riquezas que ela teceu para ele, e pensa como seria feliz se tudo voltasse a ser como antes. Ambas as situações ocorrem em momento de profunda tristeza e fragilidade da moça.

Enfim, a moça destece o seu companheiro, transmitindo a ideia de independência e, com isto, a tranquilidade volta a sua vida. "Então, como se ouvisse a chegada do sol, a moça escolheu uma linha clara. E foi passando-a devagar entre os fios, delicado traço de luz, que a manhã repetiu na linha do horizonte." (COLASANTI, 2000, p. 14). 


\section{cONwEESSOC CIENCIAESOCIEDADE

Expressivos são os danos psicológicos que esse tipo de violência pode causar, surtindo efeitos mais gravosos em relação à violência física. Ademais, importa destacar que somente a personagem tem o poder de decisão, ou seja, durante certo tempo ela submete-se aos desejos do homem na narrativa, porém somente a ela cabe a iniciativa de livrar-se dessa relação abusiva, vez que benefício algum Ihe trazia.

\section{ABORDAGEM LEGAL, DOUTRINÁRIA E JURISPRUDENCIAL}

Diante do sistema jurídico brasileiro que tendo raízes históricas tende a ser patriarcal, vê-se como sinal de avanço a garantia a isonomia às mulheres, sendo vedado o retrocesso quanto a essas garantias já conquistadas, a Constituição federal de 1988, em seu artigo $5^{\circ}$ expressamente trata sobre os direitos, deveres e garantias individuais e coletivas, para dar uma maior sustentabilidade ao princípio da dignidade da pessoa humana, base para se estabelecer a paz social nos parâmetros dos direitos humanos. Observa-se in verbis:

Art. 5o Todos são iguais perante a lei, sem distinção de qualquer natureza, garantindo-se aos brasileiros e aos estrangeiros residentes no País a inviolabilidade do direito à vida, à liberdade, à igualdade, à segurança e à propriedade, nos termos seguintes:

I - homens e mulheres são iguais em direitos e obrigações, nos termos desta Constituição. (BRASIL, 1988)

Merece destaque também as convenções internacionais consagradas e ratificadas pela legislação brasileira diante da necessidade de se regulamentar situações generalizadas de violência doméstica e que merecem uma maior atenção do Estado, dentre as quais estão a Convenção sobre a eliminação de todas as formas de discriminação contra a mulher - CEDAW, aprovada pela Assembléia Geral da ONU em 1979, e ratificada pelo Brasil após o advento da Constituição Federal em 1988 que preconizou a igualdade de gênero, e também a Convenção interamericana para prevenir, punir e erradicar a violência contra a mulher, popularmente conhecida como 


\section{CONGEESSOC CIENCIAESOCIEDADE

Convenção de Belém do Pará, sendo ratificada pelo Brasil em 1995. (PORTO, 2007, p. 16-17).

As convenções citadas acima são baseadas na Convenção dos direitos humanos e têm o objetivo de combater todas as formas de discriminação e violência sofridas por mulheres, tendo em vista que estas são um dos integrantes mais fragilizados no meio familiar e que sua ocorrência se dar principalmente no meio doméstico.

Até o advento da Lei Maria da Penha, a violência doméstica não era considerada crime, somente a lesão corporal quando praticada em âmbito e em decorrência de relações domésticas, tinha uma pena mais severa aplicada, disciplinada no Código Penal em seu art. $129, \S 9^{\circ}$. As demais condutas em âmbito familiar geravam no máximo um aumento de pena.

A lei $n^{\circ} 11.340$ de 7 de Agosto de 2006 mais conhecida como Lei Maria da Penha surgiu com o intuito de dar maior proteção à mulher em situação de violência doméstica e familiar, seja ela em qualquer de suas espécies elencadas em seu artigo $7^{\circ}$, sendo a violência psicológica o tipo abordado para maior ênfase e discussão no presente estudo. A cerca da legitimidade da lei Maria da penha, Porto (2007) esclarece melhor:

Sua legitimidade social advém, contudo, de uma realidade cruel de violência preconceituosa e histórica do homem contra a mulher, que se impõe sobre todas as críticas abolicionistas ou minimalistas, o que não significa esteja o hermeneuta dispensado de abrandar-Ihe os excessivos rigores, harmonizando-a ao ordenamento jurídico preexistente, de modo a não se engendrar um microssistema penal desconexo e isolado, opção que o encaminharia ao definhamento. (PORTO, 2007, p. 23).

Corroborando com a atenção pormenorizada que a mulher recebe do legislador, entendimentos jurisprudenciais pátrios consideram as relevâncias utilizadas no bojo dos instrumentos legais e explanam o seguinte posicionamento:

TJ-PI - Agravo de Instrumento Al 00091460520148180000 PI 201400010091466 (TJ-PI)

Data de publicação: 30/06/2015 


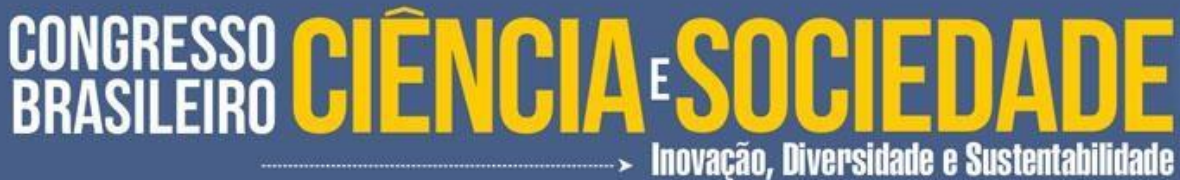

Ementa: AGRAVO DE INSTRUMENTO. AÇÃO DE RECONHECIMENTO E DISSOLUÇÃO DE UNIÃO ESTÁVEL. LEI MARIA DA PENHA. VIOLÊNCIA DOMÉSTICA CONFIGURADA. MEDIDA PROTETIVA MANTIDA. AMEAÇA. AGRESSÃO FÍSICA E PSICOLOGICA. FIXAÇÃO DE ALIMENTOS PROVISÓRIOS. VEROSSIMILHANÇA DAS ALEGAÇÕES. PERIGO DE DANO IRREPARÁVEL OU DE DIFÍCIL REPARAÇÃO. AFASTAMENTO DO LAR CONJUGAL. POSSIBILIDADE. JUSTIFICADO RECEIO. MANUTENÇÃO

DA DECISÃO HOSTILIZADA. Justificado receio de que a integridade da parte seja exposta a risco com a manutenção do convívio do casal, adequada à decisão hostilizada que deferiu o pedido de afastamento do lar e fixou os alimentos provisórios. AGRAVO CONHECIDO E IMPROVIDO. (TJ-PI, 2015, on-line).

As formas de violência elencadas no rol do artigo $7^{\circ}$ da Lei Maria da Penha deixam evidente que a ocorrência deverá ser em âmbito familiar, doméstico ou em decorrência de relações de afetividade, caso contrário não se enquadram nos parâmetros de violência contra a mulher.

\section{CONSIDERAÇÕES FINAIS}

Diante de todo o exposto, é possível concluir que a Lei Maria da Penha $\mathrm{n}^{\circ}$ 11.340/06 é um mecanismo inovador que busca amparar as mulheres em situação de violência, proporcionando uma maior proteção visando manter o equilíbrio das relações sociais, primordialmente entre homem e mulher em situação conjugal ou familiar, tal como abordado nesse estudo. Entretanto, tal instituto necessita de maior estrutura para que possa ser aplicado de forma correta e eficaz, fazendo cessar ou ao menos diminuir o aumento cada vez mais incisivo do índice de violência contra a mulher.

Em relação à violência psicológica, essa modalidade ainda enfrenta bastantes dificuldades para sua configuração, até mesmo em âmbito jurídico, tendo em vista a maneira de como se desenvolve, silenciosa e sutilmente sem que nem mesmo a vítima perceba que está sendo submetida a um tipo de violência e que esta se encaixa perfeitamente no rol constante na Lei $\mathrm{n}^{\circ} 11.340 / 06$.

Na obra a crítica maior está sobre a cultura dominante que permeia o conto do início ao final, e que pode também ser assinalado na contemporaneidade com o 


\section{CONGEESSOC CIENCIAESOCIEDADE \\ Inovação, Diversidaalle e Sustentalililitaile}

objetivo de se observar também as mudanças comportamentais das mulheres diante dessas situações de dominação e submissão.

O desejo em retomar o seu caminho sem nenhuma pressão de quem quer que seja faz com que o conto construa uma crítica construtiva quanto ao questionamento que se faz na sociedade, sobre o lugar que a mulher deve ocupar, como a mulher deve agir, e qual a garantia dada a ela para que ela exerça o seu livre arbítrio sem que seja impedida pela ação do homem.

É necessário observar que a problemática enfrentada pelas mulheres encontra- se na dúvida entre os aspectos de vida a serem ponderados, entre o patriarcal e o moderno. A transição do arcaico para o contemporâneo encontra dificuldades no preconceito dos conservadores que ainda têm a mentalidade voltada para os antigos valores e ideais, atrelando-se a mulher ao universo exclusivamente doméstico. Por outro lado, a mulher contemporânea representa o seu desejo de ser independente.

\section{REFERÊNCIAS}

BOURDIEU, Pierre. A dominação masculina. Trad. Maria Helena Kühner. 11a ed. Rio de Janeiro: Bertrand Brasil, 2012.

BRASIL. Lei Maria da Penha. Decreto Lei n. ${ }^{\circ} 11.340$, de 7 de agosto de 2006. Brasília: Senado Federal 2006. Disponível em:

https://www.planalto.gov.br/ccivil 03/ Ato2004-2006/2006/Lei/L11340.htm. Acesso em: 15 de out de 2018.

BRASIL. Constituição (1988). Constituição da República Federativa do Brasil. Brasília: Senado Federal 1988. Disponível em:

http://www.planalto.gov.br/ccivil_03/Constituicao/Constituicao.htm. Acesso em: 28 de set de 2018.

BRASIL. Código Penal. Decreto Lei n. ${ }^{\circ} 2.848$, de 7 de dezembro de 1940. Brasília: Senado Federal 1940. Disponível em: http://www.planalto.gov.br/ccivil 03/DecretoLei/Del2848.htm. Acesso em: 10 de out de 2018.

BRASIL. Convenção interamericana para prevenir, punir e erradicar a violência contra a mulher. Convenção de Belém do Pará de 9 de junho de 1994. Disponível em: 


\section{CONGEESSOC CIENCIAESOCIEDADE \\ -}

http://www.cidh.org/Basicos/Portugues/m.Belem.do.Para.htm. Acesso em: 29 de nov de 2018.

BRASIL. Convenção sobre a Eliminação de Todas as Formas de Discriminação contra as Mulheres. Decreto no 4.377, de 13 de setembro de 2002. Disponível em:

http://www.planalto.gov.br/ccivil 03/decreto/2002/d4377.htm. Acesso em: 20 de abr de 2019.

CHAUÍ, Marilena. Participando do debate sobre Mulher e Violência. In. FRANCHETTO, Bruna, CAVALCANTI, Maria Laura V. C. e HEILBORN, Maria Luiza (org.). Perspectivas Antropológicas da Mulher. 4a ed. São Paulo, Zahar Editores, 1985.

COLASANTI, Marina. A moça tecelã. 11a ed. São Paulo: Global. 2000. p 10-14. Disponível em: https://www.recantodasletras.com.br/resenhasdelivros/1413748. Acesso em: 22 de set de 2018.

CORRÊA, Mariza. $O$ sexo da Dominação. Novos Estudos CEBRAP N. ${ }^{\circ}$ 54. Julho, 1999. p. 43-53. Disponível em: https://www.sertao.ufg.br/up. Acesso em: 24 de maio de 2019.

PIAUÍ. Agravo de Instrumento Al 00091460520148180000. Relator: Des. Fernando Lopes e Silva Neto. Piauí, 30 de junho de 2015. Disponível em: https://tj- pi.jusbrasil.com.br. Acesso em: 25 de out 2018.

PORTO, Pedro Rui da Fontoura. Violência doméstica e familiar contra a mulher: Lei 11.340/06 análise crítica e sistêmica. Porto Alegre. Livraria do Advogado Editora. 2007. p. $13-30$

SAFFIOTI, Heleieth I.B. Contribuições feministas para o estudo da violência de gênero. In: Cadernos Pagu. 16a Ed. 2001. Disponível em: http://www.scielo.br/scielo.php?script=sci arttext\&pid=S010483332001000100007. Acesso em: 18 de abr de 2019. 